\title{
NOVAS OBSERVAÇÕES SOBRE O DIMORFISMO DOS RAMOS EM COFFEA ARABICA L. (1)
}

A. Carvalho, engenheiro agrônomo, e H. ANTunes Filho, engenheiro agrônomo, Secçâo de Genética do Instituto Agron.ômico de Campinas.

\section{1 - INTRODUÇÃO}

$\mathrm{Na}$ maioria dos trabalhos sôbre a propagação vegetativa do cafeeiro se tem chamado atenção para o fato de que a ocorrência do dimorfismo dos ramos, de certo modo limita o emprêgo dêsse processo de multiplicação (2, 5). Só se conseguem plantas de porte normal se, na enxertia ou estaquia, forem usadas partes de ramos ponteiros ou ortotrópicos. Os ramos laterais ou plagiotrópicos só dão origem a plantas de porte anormal, pois apenas produzem ramos laterais $(\mathbf{1}, \mathbf{3}, \mathbf{6})$.

Supunha-se, até há pouco, que na espécie Coffea arabica $L$. não poderia ocorrer a reversão de uma gema de ramo plagiotrópico para a condição ortotrópica, e que na axila das fôlhas dos ramos plagiotrópicos só existiam gemas que davam ramos plagiotrópicos ou inflorescências (2). Observações recentes vieram, entretanto, indicar que, em raríssimas ociasiões, nessa espécie também há possibilidade de gemas localizadas em ramos plagiotrópicos darem origem a ramos ortotrópicos e que, inversamente, ramos ortotrópicos podem também tomar a direção plagiotrópica. Essas modificações observadas, constituem o objeto desta comunicação.

\section{2 - OBSERVAÇÕES REALIZADAS}

Três são os cafeeiros estudados e que serão designados pela numeração adotada pela Secção de Genética.

\section{1 - PLANTA H 112-5-26-3}

Esta planta é derivada de um cruzamento entre um cafeeiro amarelo de Botucatu (Coffea arabica L. var. typica Cramer forma xanthocarpa (Catminhoá) Krug e um outro da variedade bullala (Coffea arabica L. var. bullata Cramer). Foi plantada no ripado da Estação Experimental Central de Campinas, em princípios de 1946. Caracterizava-se por apresentar fôlhas estreitas, do tipo angustifolia e frutos de côr marrom. Posteriormente, notou-se que um dos ramos laterais (plagiotrópicos) dêsse cafeeiro apresentava fôlhas mais largas, semelhantes às da var. typica. Fazendo observações nesse ramo, o Eng. Agr. A. J. T. Mendes teve sua atenção despertada para o fato de uma das gemas dêsse ramo plagiotrópico mutado ter dado um ramo com

(1) Trabalho apresentado a Begunda Reunião da Sociedado Brasileira de Botanicu, reulizada em Campinas, de 9 a 15 de janeiro de 1952. 
direção vertical, semelhante a um ramo de natureza ortotrópica (est. 1-A). Vários enxertos foram efetuados da extremidade dêste ramo, em março de 1951, verificando éle, com surpresa, que de fato se tratava de um ramo ortotrópico. Constatou assim, pela primeira vez, a existência de gemas en ramos plagiotrópicos, capazes de dar ramos de crescimento vertical, do tipo ortotıópico.

\section{2 - CAFEEIRO $J$ 48-4}

O cafeeiro J 48 é bourbon amarelo (Coffea arabica l. var. bourbm (B. Rodr.) Choussy forma xanihscarpa K.M.C.) e foi selecionado na fazenda Munte Alegre, em Jaú. Sua progênie, constituída de 20 plạntạs, acha-se em um dos lotes de seleção, da Secção de Genética, na Estação Experimental Central de Campinas. São plantas que há três anos se acham no local definitivo. Em 12 de abril de 1951, o Eng. Agr. J. E. T. Mendes verificou que uma planta dessa progênie, J 48-4, apresentava um ramo com aparência ortotrópica, desenvolvido a partir de um ramo plagiotrópico comum (est. 1-B). Foram feitos vários enxertos com êsse ramo, aproveitando-se todos os internódios. Alguns dêsses enxertos acham-se bem crescidos. Fm um dêles, desenvolveram-se duas gemas, uma de cada axila da fôlha, dando dois ramos ortotrópicos (est. 1-C, $b$ ). Em dois outros enxertos, desenvolveram-se também duas gemas, uma de cada axila de fôlha, dando, porém, uma delas origem a um ramo ortotrópico e a outra a um ramo plagiotrópico (est. 1-C, $a$ ). Em um outro enxêrto (est. 1-D) desenvolveu-se apenas um ramo ortotrópico.

Ao que parece, outra planta da mesma progênie J 48 (J 48-3) apresenta também um ramo ortotrópico, oriundo de um plagiotrópico. Enxertos dêsse ramo foram feitos, porém não pegaram. Novos enxertos estão sendo executados. Se a existência de ramos ortotrópicos oriundos de plagiotrópicos também fôr comprovada na planta $J$ 48-3, é de supor tratar-se de um característico da progênie $\mathbf{J} 48$. A fim de se verificar a possibilidade de ser êsse característico de natureza genética, autofecundações artificiais das flores já foram efetuadas em 1951 , tanto no cafeeiro J 48-4, como támbém na planta $\mathrm{J}$ 48-3.

\section{$2.3-($ AfLEIIRO $\quad 376-22$}

Trata-se de uma planta descendente de um cafeeiro selecionado da variedade bourbon -. Coffea arabica L. var. bourbon (B. Rodr.) Choussy, a qual, quando nova, apresentava ramificação ligeiramente anormal. Atualmente, a planta tem cêrca de um metro de altura e a ramificação se tornou mais anormal. Nos ramos plagiotrópicos existentes notam-se pequenos desvios na direção do crescimento, tornando-se, repentinamente, mais pendentes. Verifica-se que, em seus internódios, há uma forte tendência para se desenvolverem brotos a partir de apenas uma das axilas das fôlhas. A haste principal não mostra sinal de fasciação e se desenvolveu normalmente até a altura de 70 centímetros. A partir da axila do último par de fôlhas, notou-se, nessa altura, que a haste principal tomou um desenvolvimento 


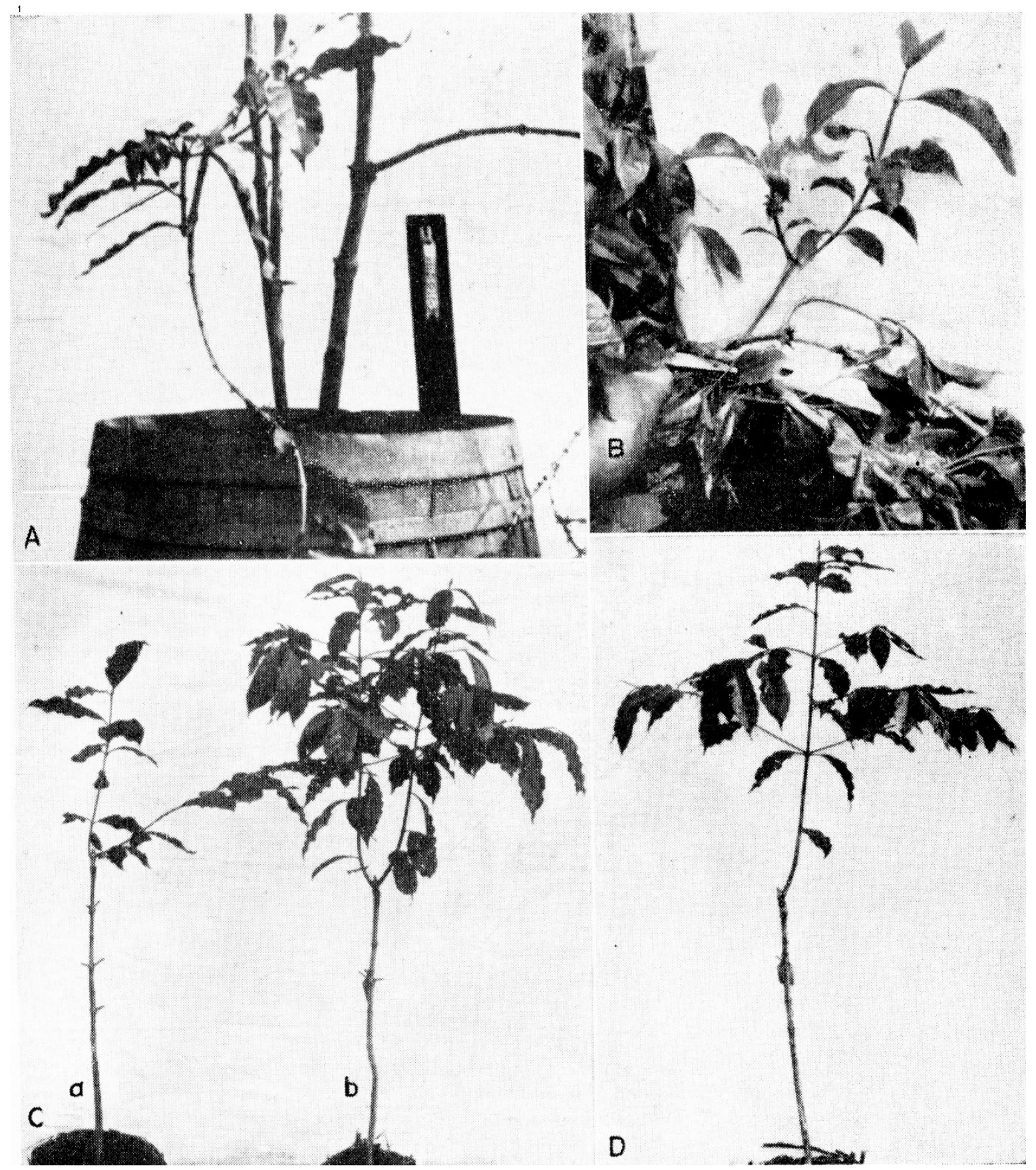

Ramos ortotrópicos desenvolvidos a parlir de ramos piagiourópicos. $A$ - Planta H 112-526-3 mostrando o ramo lateral onde se desenvolven o ramo ponteixo indicado pela flecha. $B$-. Planta J 48.4 mostrando o ramo ponteiro (podadol desenvolvido en um lateral. C e $D$-.- Enxertos do ramo mutalo da planila J 48-4. C, a -.. Desenvolven-ise uma gema lateral e uma de ponteiros; $b$ - descrnolveram-se as duas gernas dando dois ramos ponteiros; $D$-- Houve crescinento apenas de um ramo ortotrópico. 
horizontal e que as duas gemas localizadas nesse par de fôlhas se desenvolveram em ramos ortotrópicos, substituindo a haste principal em crescimento vertical. Após a produção de três pares de ramos laterais, cada um dêsses ramos ortotrópicos tomou, por sua vez, a direção horizontal, a partir de um nó, tal como a haste principal primitiva. Tem-se, dessa forma, a impressão de que, realmente, ocorreram, em três pontos, reversóes da haste principal, ortotrópica, para a condição plagiotrópica. Este exemplo é o primeiro encontrado entre milhares de cafeeiros examinados em Campinas.

\section{3 - DISCUSSÃO}

A ocorrência dêsses três casos de ramificação anormal, veio mudar a concepção que se fazia da rigidez da diferenciação somática que se opera nas gemas existentes na axila das fôlhas do cafeeiro. Os numerosos casos de enxertia e estaquia de ramos laterais ou plagiotrópicos, resultando sempre na produção exclusiva de ramos dessa natureza, indicavam que nêles existiam apenas gemas capazes de dar brotos plagiotrópicos $(\mathbf{1}, \mathbf{4}, \mathbf{5})$. As observações efetuadas nos cafeeiros $\mathrm{H}$ 112-5-26-3 e J 48-4 vieram, no entanto, indicar que, excepcionalmente, podem ocorrer nos ramos plagiotrópicos gemas que dão origem a ramos ortotrópicos. Nada se pode dizer quanto à natureza dessas gemas. Elas parecem ter se desenvolvido a partir do lenho maduro e talvez sejam adventícias. Não se pode, contudo, ter certeza da sua natureza, porquanto os ramos já se achavam bem desenvolvidos quando foram encontrados. Tôdas as vêzes que se encontrarem casos semelhantes a êsses, a verificação da natureza da gema é pratticamente impossível, pois os ramos já deverão estar bem desenvolvidos, para que possam ser classificados.

Quanto à transformaçâo observada no cafeeiro 376-22, duas hipóteses podem ser lançadas para explicá-la. A primeira seria a da transformação do ramo ortotrópico em plagiotrópico. Uma mudança na ponta do crescimento teria ocorrido, com perda da capacidade de continuar o crescimento como ramo ortotrópico. A outra hipótese seria a da inibição completa da ponta de crescimento e desenvolvimento de apenas uma das gemas do ramo plagiotrópico existente na axila do par de fôlhas terminais. Segundo esta última hipótese, a supressão do crescimento do brôto terminal deve ter ocorrido muito cedo, talvez no momento do início da diferenciação das gemas. T'em-se observado numerosas vêzes que, quando há atrofia da ponta de crescimento, são as gemas dormentes de ramos ortotrópicos, da axila das fôlhas mais próximas, que se desenvolvem tomando lugar da haste (2). Mais raramente se desenvolvem primeiramente as duas gemas plagiotrópicas, uma de cada axila e, mais tarde, as gemas de ramos ortotrópicos.

Difìcilmente será possível decidir-se quanto a essas duas hipóteses. Vários enxertos dêsises ramos terminais serão efetuados para tentar elucidar a questão.

\section{RESUMO}

Numerosos exemplos de enxertia e estaquia têm mostrado que as gemas dos ramos laterais (plagiotrópicos) do café são diferenciadas de modo que, ao se desenvolverem, não possuem a capacidade de dar ramos ponteiros 
(ortotrópicos). São descritos dois cusos independentes em que se formaram ramos ortotrópicos a partir de ramos plagiotrópicos, indicando que a perda de capacidade do ramo plagiotrópico, de produzir gemas de ramos ortotrópicos, não é total. Um outro exemplo é descrito de ramos ortotrópicos que, pelas observações até agora realizadas, parecem ter se transformado em plagiotrópicos.

\section{SUMMARY}

Vegetative propagation of coffee plant by means of graft or cuttings has frequently shown that the bud which develops into plagiotropic branches is so differentiated that it looses the capacity to produce upright growing branches (orthotropic). Two independent (ases found by A. J. T. Mendes and J. E. T. Mendes are described in this paper, of a plagiotropic branch frum which an orthotropic branch has developed, indicating that in very rare cases the differentation of the plagintropic branch is not so complete. Another case is also described of an orthotropic brinch that up to the present time sems to have changed into a plagiostropic one.

\section{IITERATL 'RA CITADA}

1. Irndt, C. H. Configuration and some tffects of light and gravity on Coffea arabira L. Amer. J. Bot. 16: 173-178. 1929.

2. Carvalho, A., C. A. Krug e J. E. T. Mendes. O dimorfismo dos mamos exn Coffea arabica L. Bragantia 10: 151-150. 1950.

3. Carvalho, A. e C. A. Krug. Genética de Coffen XIIl -- Hereditariedade do earacterístico crecta em Coffer arabira L. Bragantia 10: 321-328. 1950.

4. Gillet, S. Vegetative propagation of exfere. Valay. agric. J. 23: 488-492. 1935.

5. Mendes, J. E. T. A unxertia do cufexiro I. Bol. téc. Inst. agron., Campinas. 39: 1-18. 1938.

6. Mendes, J. E. T. Enxertia do cafueiro - Borbulhis. Rev. Dep. Nac. Café, Rio de J. 20: 506-510. 1943 . 